\title{
Flumatinib Mesylate
}

National Cancer Institute

\section{Source}

National Cancer Institute. Flumatinib Mesylate. NCI Thesaurus. Code C117723.

The orally bioavailable, mesylate salt form of the tyrosine kinase inhibitor flumatinib, with potential antineoplastic activity. Upon administration, flumatinib inhibits the wild-type forms of Bcr-Abl, platelet-derived growth factor receptor (PDGFR) and mast/stem cell growth factor receptor (SCFR; c-Kit) and forms of these proteins with certain point mutations. This results in the inhibition of both Bcr-Abl-, PDGFR- and c-Kit-mediated signal transduction pathways, and the proliferation of tumor cells in which these kinases are overexpressed. Bcr-Abl fusion protein is an abnormal, constitutively active enzyme expressed in Philadelphia chromosome positive chronic myeloid leukemia (CML), acute lymphoblastic leukemia (ALL) or acute myelogenous leukemia (AML). PDGFR, upregulated in many tumor cell types, is a receptor tyrosine kinase essential to cell migration and the development of the microvasculature. c-kit, a receptor tyrosine kinase mutated and constitutively activated in certain tumors, plays a key role in tumor cell survival, proliferation, and differentiation. 